\title{
The Sensitivity of the Hydrological Cycle to Internal Climate Variability versus Anthropogenic Climate Change ${ }^{\mathscr{b}}$
}

\author{
RYAN J. KRAMER AND BRIAN J. SODEN \\ Rosenstiel School of Marine and Atmospheric Science, University of Miami, Miami, Florida
}

(Manuscript received 12 June 2015, in final form 9 February 2016)

\begin{abstract}
In response to rising $\mathrm{CO}_{2}$ concentrations, climate models predict that globally averaged precipitation will increase at a much slower rate than water vapor. However, some observational studies suggest that globalmean precipitation and water vapor have increased at similar rates. While the modeling results emphasize changes at multidecadal time scales where the anthropogenic signal dominates, the shorter observational record is more heavily influenced by internal variability. Whether the physical constraints on the hydrological cycle fundamentally differ between these time scales is investigated. The results of this study show that while global-mean precipitation is constrained by radiative cooling on both time scales, the effects of $\mathrm{CO}_{2}$ dominate on multidecadal time scales, acting to suppress the increase in radiative cooling with warming. This results in a smaller precipitation change compared to interannual time scales where the effects of $\mathrm{CO}_{2}$ forcing are small. It is also shown that intermodel spread in the response of atmospheric radiative cooling (and thus global-mean precipitation) to anthropogenically forced surface warming is dominated by clear-sky radiative processes and not clouds, while clouds dominate under internal variability. The findings indicate that the sensitivity of the global hydrological cycle to surface warming differs fundamentally between internal variability and anthropogenically forced changes and this has important implications for interpreting observations of the hydrological sensitivity.
\end{abstract}

\section{Introduction}

Understanding the response of precipitation to climate change has become a topic of great focus in the climate science community, given the potential societal consequences. Climate models indicate that atmospheric water vapor will increase with warming at a rate consistent with that expected from the Clausius-Clapeyron equation $\left(\sim 7 \% \mathrm{~K}^{-1}\right)$. In contrast, results from modeling studies indicate that the increase in global-mean precipitation $P$ with warming is much lower $\left(\sim 2 \% \mathrm{~K}^{-1}\right)$ and dictated by energetic constraints rather than moisture availability (Allen and Ingram 2002; Held and Soden 2006; Vecchi and Soden 2007; Stephens and Ellis 2008). This rate of change can be interpreted as the sensitivity of $P$ to a

Supplemental information related to this paper is available at the Journals Online website: http://dx.doi.org/10.1175/ JCLI-D-15-0408.s1.

Corresponding author address: Ryan J. Kramer, Rosenstiel School of Marine and Atmospheric Science, University of Miami, 4600 Rickenbacker Cswy, Miami, FL 33149.

E-mail: rkramer@rsmas.miami.edu change in the global-mean near-surface air temperature $\Delta T_{s}$. Herein, we use linear regression to quantify the sensitivity of a variable to changes in global-mean $T_{s}$ and, for brevity, represent this sensitivity as a derivative (i.e., $d P / d T_{s}$ represents the linear regression slope of globalmean precipitation to changes in global-mean $T_{s}$ ).

Changes to the globally averaged atmospheric energy budget can be expressed as

$$
\Delta R=L \Delta P+\Delta \mathrm{SH},
$$

where $\Delta R$ is the change in atmospheric radiative cooling (defined as positive for increased cooling); $L \Delta P$ is the latent heat flux change, where $L$ is the latent heat of vaporization; and $\Delta \mathrm{SH}$ is the sensible heat flux change. Calculated as the difference between the net radiation balance at the surface and at the top of the atmosphere (TOA), $R$ increases as the surface warms, as a result of a growing energy loss from longwave (LW) emission. This increase in $R$ must be balanced by an increase in $L P$ in order to maintain equilibrium in the atmosphere's energy budget. The change in sensible heat $\Delta \mathrm{SH}$ also contributes to this balance, but is smaller in magnitude (Previdi 2010; Stephens and Ellis 2008). 
Attempts have been made to quantify precipitation and water vapor sensitivity from observations. Water vapor increases are tightly coupled to surface warming in observations, and the sensitivity of water vapor is robustly observed to be $6 \%-7 \% \mathrm{~K}^{-1}$ (Wentz and Schabel 2000; Trenberth et al. 2005; O'Gorman et al. 2012), in agreement with models. Precipitation and surface temperature change demonstrate weaker coupling in the observations (O'Gorman et al. 2012; Allan et al. 2014), and more uncertainty in observed $d P / d T_{s}$. Wentz et al. 2007 determined that $P$ has increased at a rate of roughly $6 \% \mathrm{~K}^{-1}$ by using observations from 1987 to 2006 , which is much larger than modeled sensitivities. Other studies have shown observed $d P / d T_{s}$ to be $2-3 \% \mathrm{~K}^{-1}$ (Arkin et al. 2010; O'Gorman et al. 2012; Allan et al. 2014), in closer agreement with the models. The sensitivity of $P$ is also dependent on the time period used (John et al. 2009). For example, the sensitivity obtained using data from the Global Precipitation Climatology Project (Huffman et al. 2009) and HadCRUT4 temperature measurements (Morice et al. 2012) is 3.4\% $\mathrm{K}^{-1}$ for the years 1989-2010 (O'Gorman et al. 2012) and $2.8 \% \mathrm{~K}^{-1}$ for the years 1988-2010 (Allan et al. 2014).

It is well documented that precipitation is difficult to measure with confidence on a global scale and only a few decades of reliable data are available [see discussion in Stephens and Ellis (2008) and Arkin et al. (2010)]. Internal variability in these short record lengths may contribute to the uncertainties described above and limit the applicability of the observational data to better understand anthropogenic climate change. Without intending to completely reconcile observations with model results, we investigate whether there is a fundamental difference between the constraints on $\Delta P$ under anthropogenic climate change and internal climate variability. This is not simply an academic question, but one that has important practical implications, since it is the shorter-time-scale internal variability that frequently dominates the observational record.

Using a coordinated set of climate model simulations forced with increasing $\mathrm{CO}_{2}$, we examine the energetic constraints on the hydrological cycle at both time scales by comparing $d R / d T_{s}, d P / d T_{s}, d \mathrm{SH} / d T_{s}$, and the sensitivity of column-integrated water vapor $d W / d T_{s}$ for changes on short (interannual) and long (multidecadal) time scales. We also determine whether the balance between $\Delta R$ and $L \Delta P$ holds at these different time scales and assess the effects of clouds on these relationships.

\section{Data and methods}

This study uses monthly mean output from simulations conducted with 23 coupled ocean-atmosphere general circulation models (CGCMs) included in phase
TABLE 1. CMIP5 models used in this study. Archived data from 1 pctCO 2 and abrupt $4 x \mathrm{xCO} 2$ experiments were used. Models have been labeled with a number used in multiple figures for identification. (Expansions for model acronyms are available at http:// www.ametsoc.org/PubsAcronymList.)

\begin{tabular}{rll}
\hline \hline No. & \multicolumn{1}{c}{ Model } & \multicolumn{1}{c}{ Country } \\
\hline 1 & ACCESS1.0 & Australia \\
2 & ACCESS1.3 & Australia \\
3 & BCC_CSM1.1 & China \\
4 & BCC_CSM1.1(m) & China \\
5 & CanESM2 & Canada \\
6 & CCSM4 & United States \\
7 & CNRM-CM5 & France \\
8 & CNRM-CM5.2 & France \\
9 & CSIRO Mk3.6.0 & Australia \\
10 & GFDL CM3 & United States \\
11 & GFDL-ESM2G & United States \\
12 & GFDL-ESM2M & United States \\
13 & HadGEM2-ES & United Kingdom \\
14 & INM-CM4.0 & Russia \\
15 & IPSL-CM5A-LR & France \\
16 & IPSL-CM5B-LR & France \\
17 & MIROC5 & Japan \\
18 & MIROC-ESM & Japan \\
19 & MPI-ESM-LR & Germany \\
20 & MPI-ESM-MR & Germany \\
21 & MPI-ESM-P & Germany \\
22 & MRI-CGCM3 & Japan \\
23 & NorESM1-M & Norway \\
\hline
\end{tabular}

5 of the Coupled Model Intercomparison Project (CMIP5). In one set of simulations, $\mathrm{CO}_{2}$ concentration in the atmosphere is increased $1 \% \mathrm{yr}^{-1}$ to a quadrupling from preindustrial values (referred to as 1 pctCO2 simulations) (Taylor et al. 2012); however, this study only uses output that extends to a doubling of $\mathrm{CO}_{2}$ (years 1-70), since some models stop increasing $\mathrm{CO}_{2}$ after this point. These $1 \mathrm{pctCO} 2$ experimental runs allow us to determine how the hydrological cycle responds to temperature change and how external forcing under transient climate conditions alters its response. To assess the direct response of the hydrological cycle to surface temperature change, separate from external forcing, we also use simulations where $\mathrm{CO}_{2}$ is immediately quadrupled from preindustrial concentrations and then held fixed (referred to as abrupt $4 \mathrm{xCO} 2$ simulations). In contrast to simulations of realistic climate projections, which include additional external forcings and account for climate mitigation efforts, $1 \mathrm{pctCO} 2$ and abrupt $4 \mathrm{xCO} 2$ are idealized, experimental simulations, designed to isolate the effects of surface warming from the direct effects of $\mathrm{CO}_{2}$. If multiple ensemble runs were conducted for a model, only the first realization is used. Models are listed in Table 1.

Each variable used in the study, besides $R$, is available as direct model output. The results for $R$ are derived by 

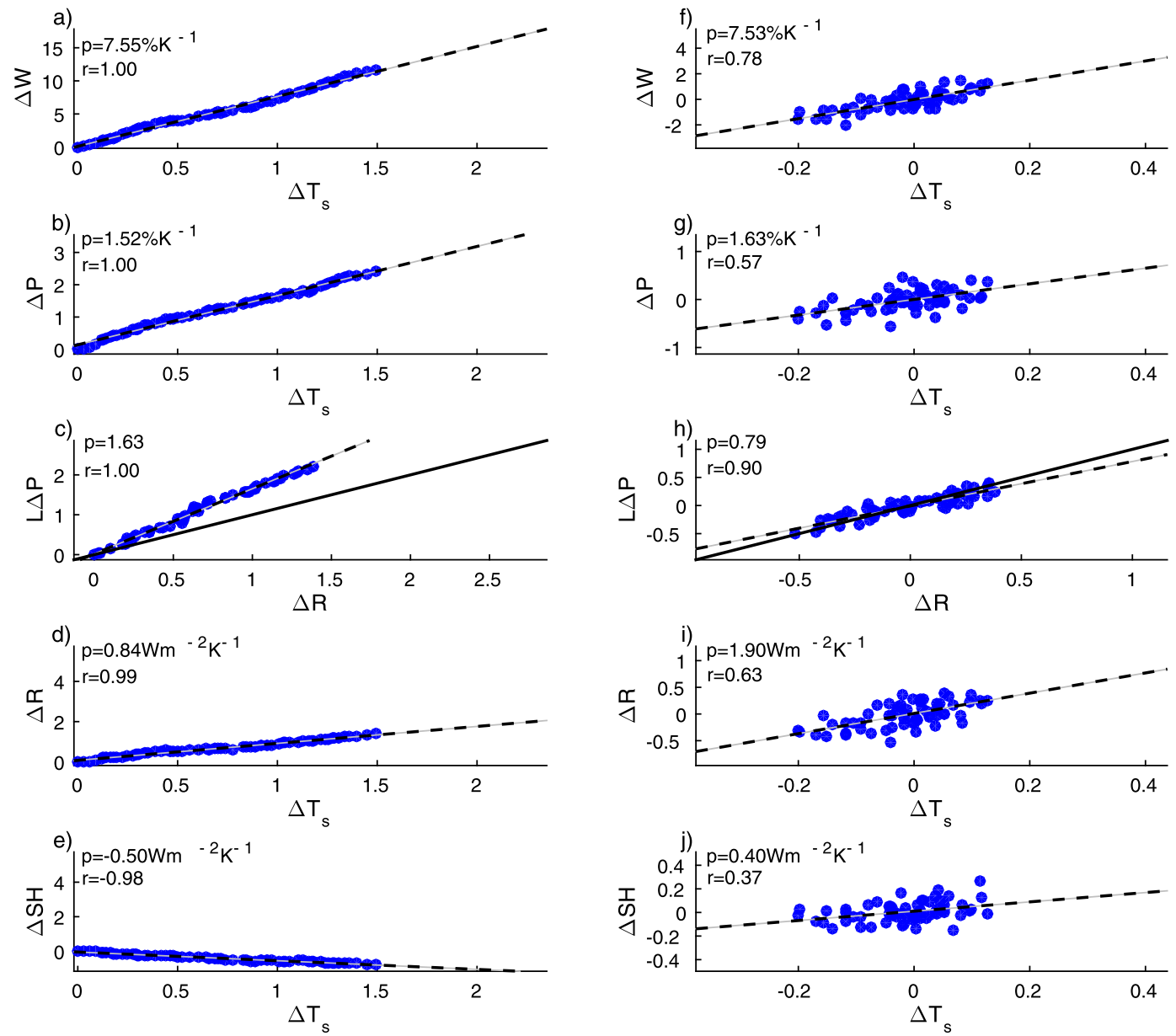

FIG. 1. Scatterplot of the global-mean change in quantities for the ACCESS1.3 model, using the 1pctCO2 simulation. Results are shown for (a),(f) $\Delta W$ vs $\Delta T_{s}$, (b),(g) $\Delta P$ vs $\Delta T_{s}$, (c),(h) $L \Delta P$ (precipitation in energy form, latent heat flux change) vs $\Delta R$, (d),(i) $\Delta R$ vs $\Delta T_{s}$, and (e),(j) $\Delta$ SH vs $\Delta T_{s}$ for (a)-(e) ACC and (f)-(j) ICV. Linear least squares regression lines (dashed black) and one-to-one lines (solid black) are shown as necessary. Linear regression slope $p$ and correlation coefficient $r$ are displayed.

using modeled net LW and shortwave (SW) radiative fluxes at the surface and TOA. The monthly mean output is averaged to annual means and a time series of anomalies is calculated for each variable using the first 10 years of data as a baseline. Many quantities are converted to percentage changes with respect to the mean of the baseline data, and results presented are areal-weighted global means, unless otherwise specified. To isolate longer-scale variability, a 10-yr moving average is applied to the time series of each globally averaged variable as a low-pass filter. We consider the resultant low-frequency variability to represent anthropogenic climate change (ACC). These data are compared to shorter-scale variability, which is calculated by subtracting the ACC time series from the total time series. These shorter time scales of a year to a decade represent internal climate variability (ICV). The same methodology is applied to both the 1 pctCO2 and abrupt $4 \mathrm{xCO} 2$ simulations. On subannual time scales, the atmosphere is not subject to the same energy balance constraints discussed in section 1 (Fasullo and Trenberth 2008; Donohoe and Battisti 2013), and therefore these time scales are not analyzed.

\section{Results}

a. Water vapor, radiative cooling, precipitation, and sensible heat flux changes

To assess whether the hydrological constraints on $\Delta P$ are time-scale dependent, we calculate the sensitivity of each component of the atmospheric energy budget (and the sensitivity of $W$ ) by linearly regressing the time series of the respective variable to the time series of $\Delta T_{s}$. The linear regression slope represents the sensitivity. As an illustration, Fig. 1 compares scatterplots of column-integrated water vapor change $\Delta W$ versus $\Delta T_{s}$, precipitation change 

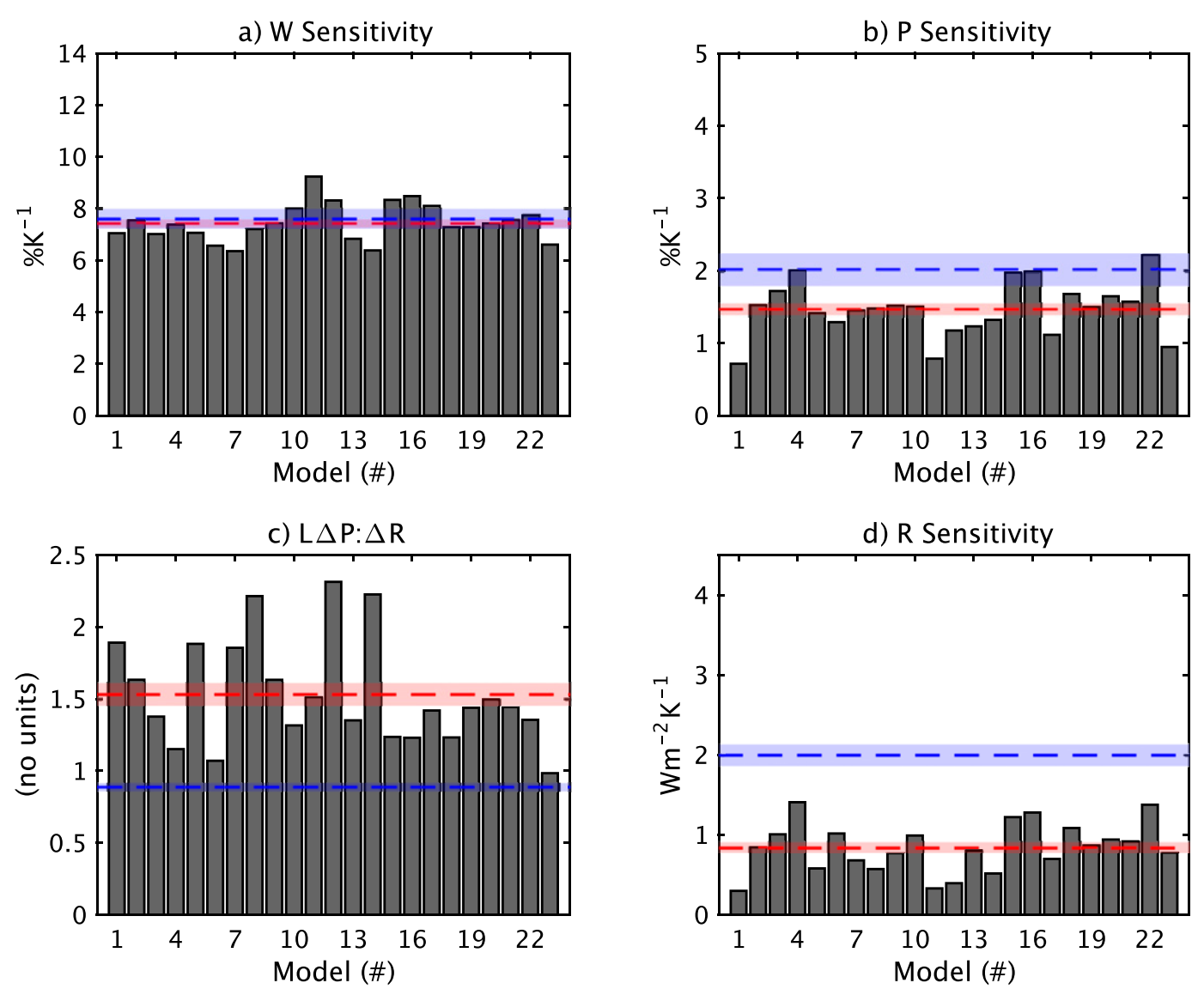

FIG. 2. ACC global-mean (a) $W$ sensitivity, (b) $P$ sensitivity, (c) ratio of $L \Delta P$ to $\Delta R$, and (d) $R$ sensitivity for each CMIP5 model listed in Table 1 for 1pctCO2 simulations. Dashed red line represents the ensemble mean (ACC). Ensemble-mean sensitivity for ICV (blue dashed line) is displayed for comparison. Shaded regions of the same color show plus or minus one standard error of the mean.

$\Delta P$ versus $\Delta T_{s}, L \Delta P$ versus $\Delta R, \Delta R$ versus $\Delta T_{s}$, and $\Delta \mathrm{SH}$ versus $\Delta T_{s}$ for ACC (Figs. 1a-e) and ICV (Figs. 1f-j) from the 1 pctCO2 simulation for the ACCESS1.3 model-the model whose behavior is closest to the ensemble mean for each variable.

The correlation coefficient and linear regression slope are displayed for each relationship. All variable comparisons in Fig. 1 exhibit a linear relationship, but there are differences in the magnitude of the sensitivities, or slopes, between time scales. Although the correlation coefficients are generally lower for ICV, the reduced degrees of freedom for ACC likely contribute to its higher correlation coefficients. However, the correlation of $\Delta \mathrm{SH}$ versus $\Delta T_{s}$ for ICV is considerably lower than the correlations of the other relationships at this time scale and will be addressed below.

Plots similar to Fig. 1 have been created for each model and are included in the supplemental material (see Fig. S1). Plots have similarly been created for the abrupt4xCO2 simulations (Fig. S2). Additionally, Fig. S3 in the supplemental material confirms that the energy budget in Eq. (1), expressed in terms of sensitivity, holds for both ACC and ICV. The slight deviations from equality between $d R / d T_{s}$ and the sum of $L d P / d T_{s}$ and $d \mathrm{SH} / d T_{s}$ reflect the uncertainties in using linear regression to quantify the sensitivities. Relevant results across models are summarized below.

Figures 2 and 3 show sensitivities for the 1 pctCO2 simulations from each model for ACC and ICV, respectively, calculated following the methodology outlined above. In both figures, the red dashed lines indicate ensemble means for ACC while the blue dashed lines indicate ensemble means for ICV. Ensemble-mean $d W / d T_{s}$ (Figs. 2a and 3a) is nearly identical for ACC $\left(7.4 \% \mathrm{~K}^{-1}\right)$ versus ICV $\left(7.6 \% \mathrm{~K}^{-1}\right)$. Ensemble-mean $d P / d T_{s}$ (Figs. 2b and 3b) is less than $d W / d T_{s}$ for both ACC and ICV, in agreement with past studies (Allen and Ingram 2002; Held and Soden 2006 and others). Most importantly, we find that $d P / d T_{s}$ is systematically lower for ACC $\left(1.5 \% \mathrm{~K}^{-1}\right)$ compared to ICV $\left(2.0 \% \mathrm{~K}^{-1}\right)$. 


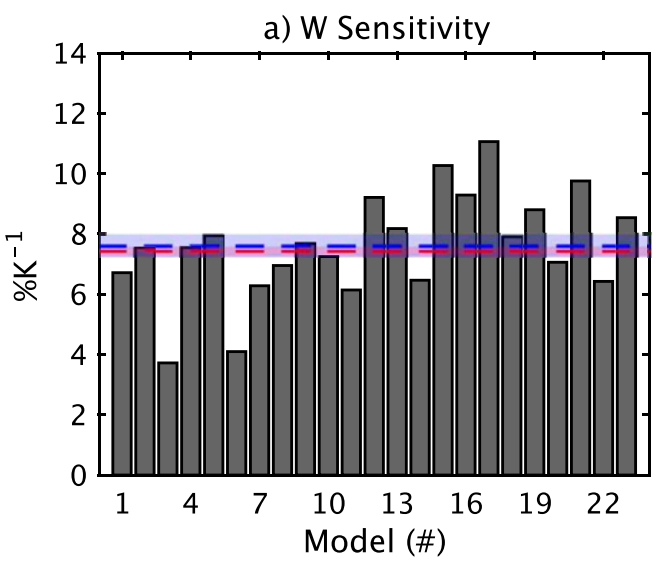

c) $\mathrm{L} \Delta \mathrm{P}: \Delta \mathrm{R}$

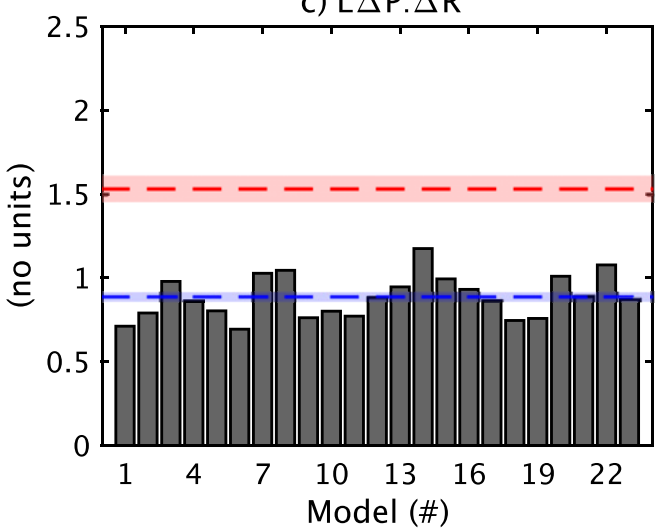

b) P Sensitivity

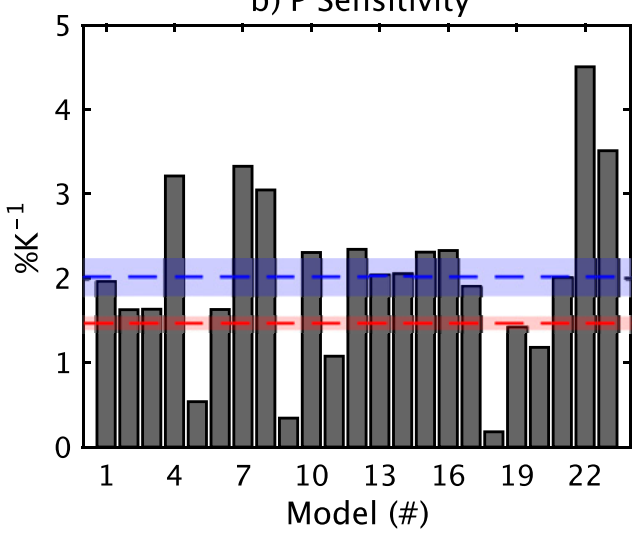

d) R Sensitivity

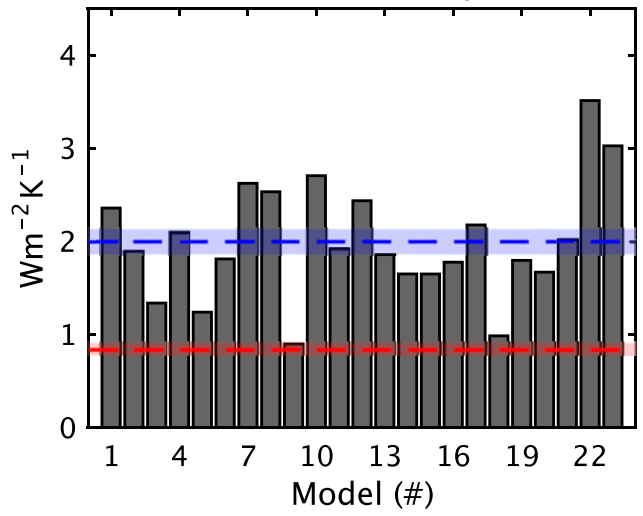

FIG. 3. ICV global-mean (a) $W$ sensitivity, (b) $P$ sensitivity, (c) ratio of $L \Delta P$ to $\Delta R$, and (d) $R$ sensitivity for each CMIP5 model listed in Table 1 for 1 pctCO2 simulations. Dashed blue line represents the ensemble mean (ICV). Ensemble-mean sensitivity for ACC (red dashed line) is displayed for comparison. Shaded regions of the same color show plus or minus one standard error of the mean.

As expected given the physical constraints outlined above, the ratio of $L \Delta P$ to $\Delta R$ maintains nearly a one-to-one relationship; however, on average $L \Delta P$ increases more than $\Delta R$ for ACC (Fig. 2c), and less than $\Delta R$ for ICV (Fig. 3c). This difference requires compensating differences in $\Delta \mathrm{SH}$ in order to maintain equilibrium, which is discussed in more detail below.

Similar to $d P / d T_{s}, d R / d T_{s}$ is also smaller for ACC (Fig. 2d) compared to ICV (Fig. 3d), with ensemblemean values of 0.8 and $2.0 \mathrm{~W} \mathrm{~m}^{-2} \mathrm{~K}^{-1}$, respectively. Thus, $R$ increases more slowly with surface warming for ACC relative to ICV.

In the $1 \mathrm{pctCO} 2$ simulations, $d \mathrm{SH} / d T_{s}$ is robustly negative across models for ACC (Fig. 4a), in agreement with past studies of anthropogenically forced climate change simulations (Lambert and Webb 2008; Stephens and Ellis 2008). However, for ICV the sensible heat flux tends to increase with surface warming rather than decrease (Fig. 4b), and exhibits a less coherent relationship with temperature (Fig. 1j and Fig. S1). This different response of $\mathrm{SH}$ to warming is consistent with the findings in Figs. 2c and 3c that $L P$ increases more than $R$ for ACC, but increases less than $R$ for ICV. For ACC, SH decreases with warming and $R$ increases with warming, both contributing to increased atmospheric energy loss. Therefore, based on Eq. (1), LP must increase more than $R$ to fully compensate for this energy loss (Fig. 2c). For ICV, however, SH increases with warming, offsetting some of the energy loss associated with increased $R$. Therefore, $L P$ increases less than $R$ (Fig. $3 c$ ).

The effects of $\mathrm{CO}_{2}$ forcing are responsible for the differences in $d P / d T_{s}$ and $d R / d T_{s}$ between time scales (Figs. 2b,d and 3b,d). Increasing $\mathrm{CO}_{2}$ concentrations decreases the net outgoing TOA radiation more than it increases the downwelling surface radiation. This acts to heat the atmosphere, decreasing $R$, and thereby suppressing the increase in $P$ required to balance the energy budget (Allen and Ingram 2002; Yang et al. 2003; Bony et al. 2013). This mechanism is effective for ACC but not for ICV, since the increases in $\mathrm{CO}_{2}$ are much larger on 

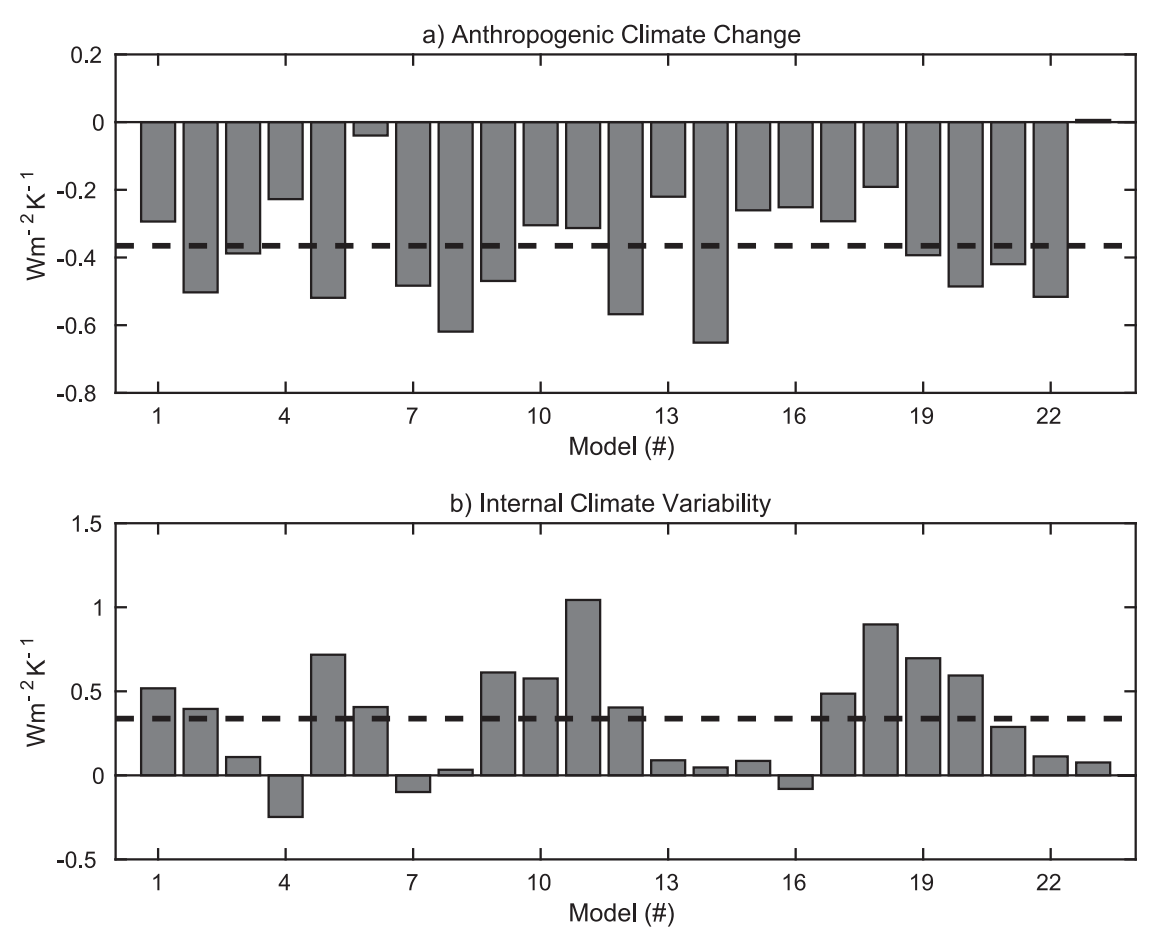

FIG. 4. Global-mean SH sensitivity for $1 \mathrm{pctCO} 2$ simulations for (a) ACC and (b) ICV for each model listed in Table 1. Dashed black lines show ensemble means.

multidecadal time scales (ACC) than interannually (ICV). Therefore, the responses of $R$ and $P$ to direct $\mathrm{CO}_{2}$ forcing are greater on multidecadal time scales, and, consequently, both $d P / d T_{s}$ and $d R / d T_{s}$ are lower for ACC compared to ICV.

Under the $1 \mathrm{pctCO} 2$ simulations, $R$, and therefore $P$, respond concurrently to changes in $\mathrm{CO}_{2}$ concentrations and rising temperatures. When compared to the $1 \mathrm{pctCO} 2$ simulations, analysis of the abrupt $4 \mathrm{xCO} 2$ simulations allows us to isolate each component and determine their relative contributions to the differences in sensitivity between ACC and ICV.

Figures 5 and 6 show sensitivities for ACC and ICV time scales, respectively, for the abrupt $4 \mathrm{xCO} 2$ simulations. In contrast to the $1 \mathrm{pctCO} 2$ simulations, the ensemblemean $d P / d T_{s}$ results are nearly identical for ACC and ICV in the abrupt $4 \mathrm{xCO} 2$ simulations (Figs. $5 \mathrm{~b}$ and $6 \mathrm{~b}$ ). Similarly, the difference in $d R / d T_{s}$ between ACC and ICV that occurs in the 1 pctCO2 simulations is almost completely absent in the abrupt4xCO2 simulations (Figs. $4 \mathrm{~d}$ and $5 \mathrm{~d}$ ). A slight difference between time scales does exist for ensemble-mean $d R / d T_{s}$ (and $d W / d T_{s}$ ) and likely reflects the unique aspects of the idealized abrupt $4 \mathrm{xCO} 2$ simulations, such as rapid land-sea warming contrasts spurred by the instantaneous $\mathrm{CO}_{2}$ quadrupling. Since $d P / d T_{s}$ and $d R / d T_{s}$ are reduced for ACC relative to ICV in the $1 \mathrm{pctCO} 2$ simulations, but not in the abrupt $4 \mathrm{xCO} 2$ simulations, this confirms that $\mathrm{CO}_{2}$ effects are responsible for the differences between time scales.

Unlike $d R / d T_{s}$ (and $d P / d T_{s}$ ), the difference in $d \mathrm{SH} / d T_{s}$ between time scales observed in the $1 \mathrm{pctCO} 2$ simulations also occurs in the abrupt $4 \mathrm{xCO} 2$ simulations, where again $d \mathrm{SH} / d T_{s}$ is negative across most models for ACC (Fig. 7a) but tends to be positive for ICV (Fig. 7b). Because $\mathrm{CO}_{2}$ does not change after the first day of the model integration, it is the temperature-dependent response of the sensible heat flux, and not $\mathrm{CO}_{2}$-induced changes, which is responsible for the differences in $d \mathrm{SH} / d T_{s}$ between time scales.

Changes in sensible heat flux are strongly related to changes in the surface-air temperature difference $\Delta\left(T_{\mathrm{sk}}-T_{s}\right)$, where $T_{\mathrm{sk}}$ is the skin temperature, or sea surface temperature over oceans, and $T_{s}$ is the nearsurface air temperature. This relationship is explored in Fig. 8, which displays the linear regression slope of local changes in sensible heat flux $\Delta \mathrm{SH}$ to changes in global-mean near-surface air temperature $\Delta T_{s}$ for ACC (Fig. 8a) and ICV (Fig. 8b) for 1pctCO2 simulations. Maps of the regression between local changes in surfaceair temperature difference $\Delta\left(T_{\mathrm{sk}}-T_{s}\right)$ to changes in global-mean near-surface air temperature $\Delta T_{s}$ are also presented for ACC (Fig. 8c) and ICV (Fig. 8d).

For ACC, the sensitivity of $\mathrm{SH}$ is uniformly negative over oceans, and tends to be positive over land. This is 

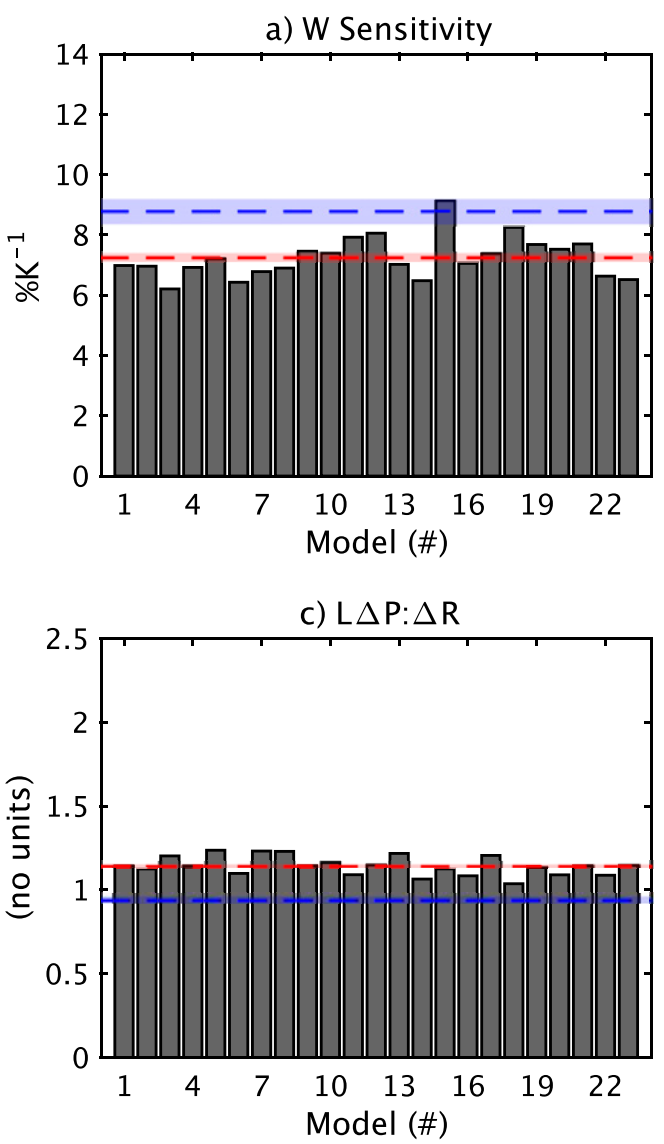

b) P Sensitivity

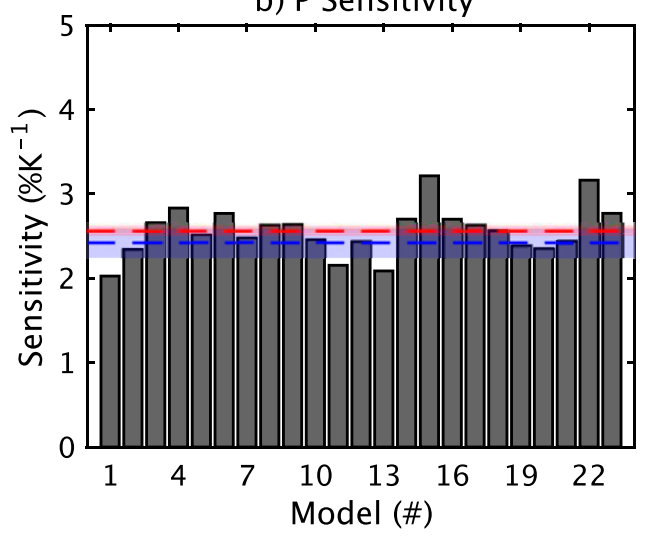

d) R Sensitivity

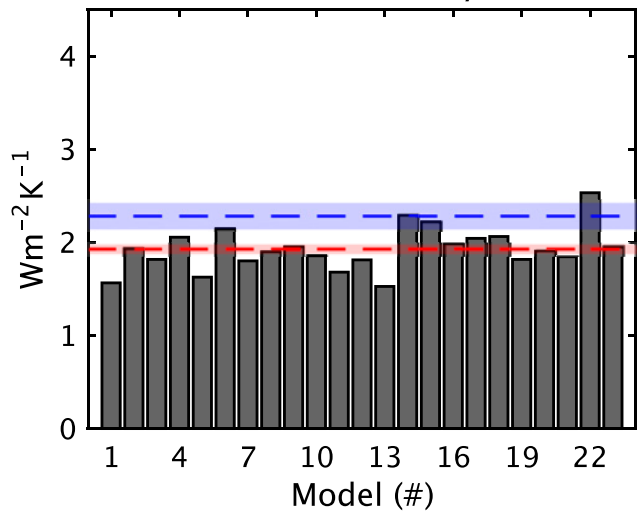

FIG. 5. As in Fig. 2, but for abrupt4xCO2 simulations.

consistent with the spatial pattern of $\Delta\left(T_{\mathrm{sk}}-T_{s}\right)$. Positive $d \mathrm{SH} / d T_{s}$ over land can be explained by moisture constraints (Sherwood and Fu 2014). Here, $L \Delta P$ is restricted by limited moisture availability over land; therefore, $\Delta \mathrm{SH}$ must be positive to maintain the atmospheric energy demands. The positive $\mathrm{SH}$ sensitivity requires enhanced warming at the surface, which the positive $\left(T_{\mathrm{sk}}-T_{s}\right)$ sensitivities over land reflect.

We are unaware of a similar hypothesis that explains the negative $d \mathrm{SH} / d T_{s}$ over the ocean. The difference in the response of sensible heat flux between ACC and ICV suggests that the reduction in $\mathrm{SH}$ is not an intrinsic response of the ocean-atmosphere interface to surface warming. For ICV,$d \mathrm{SH} / d T_{s}$ is highly nonuniform over ocean, exhibiting a spatial pattern that is closely tied to the local changes in the surface-air temperature difference (Figs. 8b,d). This is consistent with the lack of coherence of global-mean $\Delta$ SH with $\Delta T_{s}$ displayed in Fig. 1 and Fig. S1.

Additionally, from a subset of models, we make use of simulations where landmasses are removed (a so-called aquaplanet simulation) and a uniform surface warming of $4 \mathrm{~K}$ is applied. Ensemble-mean $d \mathrm{SH} / d T_{s}$ is negative in these simulations for most locations locally (not shown) and for the global average $\left(-0.45 \mathrm{~W} \mathrm{~m}^{-2} \mathrm{~K}^{-1}\right)$. This suggests that the $\mathrm{SH}$ decrease with warming is not dependent on the presence of land.

\section{b. Effects of clouds on radiative cooling and precipitation changes}

Clouds play a significant role in the atmospheric energy budget and, therefore, are worthy of discussion within the context of precipitation changes, especially with regard to intermodel spread, which is notably greater in both $d P / d T_{s}$ and $d R / d T_{s}$ for ICV compared to ACC (Figs. 2b,d and 3b,d). Total-sky atmospheric radiative cooling $R$ comprises clear-sky $R_{\mathrm{clr}}$ and cloud contributions to atmospheric heating and cooling $R_{\mathrm{cld}}$, defined as

$$
R_{\text {cld }}=R-R_{\text {clr }} .
$$

The sensitivities of $R_{\text {clr }}$ and $R_{\text {cld }}$ are compared to the sensitivity of $R$ in Fig. 9, where each point represents the global mean for a single model. The figures, and all of the remaining analysis below, are shown for the $1 \mathrm{pctCO} 2$ simulations, but the results are nearly identical for the abrupt $4 \mathrm{xCO} 2$ simulations. 

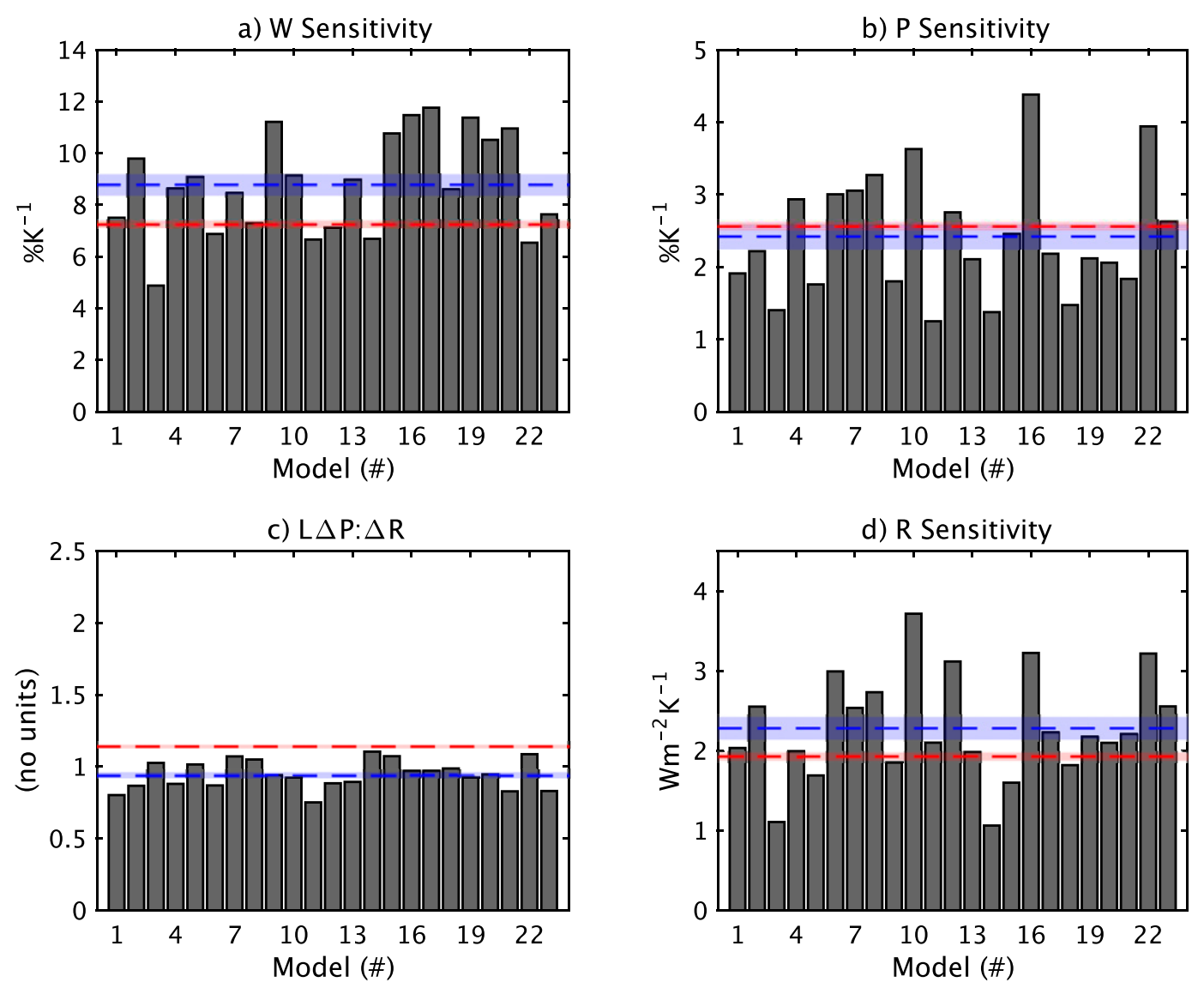

FIG. 6. As in Fig. 3, but for abrupt4xCO2 simulations.

In agreement with previous studies (Stephens and Ellis 2008; Lambert and Webb 2008; Previdi 2010; Lambert et al. 2015), ensemble-mean $d R_{\mathrm{cld}} / d T_{s}$ is negative, indicating that the global and column-averaged effect of warming-induced changes in cloudiness and cloud forcing is to reduce radiative cooling (i.e., heat the atmosphere). This holds for both ACC (Fig. 9a) and ICV (Fig. 9b). Ensemble-mean $d R_{\text {cld }} / d T_{s}$ for ACC $\left(-0.42 \mathrm{~W} \mathrm{~m}^{-2} \mathrm{~K}^{-1}\right)$ is comparable to the ensemble-mean "cloud radiative forcing change" $\left(0.55 \mathrm{~W} \mathrm{~m}^{-2} \mathrm{~K}^{-1}\right)$ in Fig. 6d from Previdi (2010), a synonymous quantity defined in that work to be positive for atmospheric heating. Previdi (2010) considered time scales representative of ACC and concluded that cloud feedback is significantly responsible for the intermodel spread in $d R / d T_{s}$, with a contribution (standard deviation of $0.20 \mathrm{~W} \mathrm{~m}^{-2}$ ) to the spread comparable to the clear-sky component (standard deviation of $0.22 \mathrm{~W} \mathrm{~m}^{-2}$ ), represented as the combined lapse rate plus water vapor feedback contribution. In a similar analysis, O'Gorman et al. (2012) concluded that cloud feedback was the largest contributor to intermodel spread in $d R / d T_{s}$. In contrast, our results show that for ACC, the intermodel spread of the clear-sky component accounts for a much greater portion of the model spread in $d R / d T_{s}$ than cloud effects do. This is consistent with the findings by Pendergrass and Hartmann (2014).

Since the intermodel spread of $d R_{\mathrm{clr}} / d T_{s}$ and $d R_{\mathrm{cld}} / d T_{s}$ sum to the intermodel spread of $d R / d T_{s}$, the linear regression slopes listed in Fig. 9 are a measure of each component's contribution to the spread in $d R / d T_{s}$. Standard error is used as a measure of slope uncertainty. For ACC, spread in $d R_{\mathrm{clr}} / d T_{s}$ accounts for $78 \% \pm 15 \%$ of the intermodel spread in $d R / d T_{s}$, while $d R_{\mathrm{cld}} / d T_{s}$ accounts for the remaining $22 \% \pm 15 \%$ (Fig. 9a). In contrast, for ICV, $d R_{\mathrm{cld}} d d T_{s}$ spread accounts for the majority $(60 \% \pm 12 \%)$ of the spread in $d R / d T_{s}$. Additionally, the ranges of $d R_{\mathrm{clr}} / d T_{s}$ are similar for ICV and ACC time scales (1.6 and $1.3 \mathrm{~W} \mathrm{~m}^{-2} \mathrm{~K}^{-1}$, respectively), while the range of $d R_{\mathrm{cld}} / d T_{s}$ is much larger for ICV $\left(2.0 \mathrm{~W} \mathrm{~m}^{-2} \mathrm{~K}^{-1}\right)$, compared to ACC $\left(1.0 \mathrm{~W} \mathrm{~m}^{-2} \mathrm{~K}^{-1}\right)$. Therefore, the increased intermodel spread in $d R / d T_{s}$, and subsequently $d P / d T_{s}$, for ICV compared to ACC is largely due to increased intermodel spread in cloud radiative effects. The increased spread in $d R_{\text {cld }} / d T_{s}$ for ICV relative to ACC suggests that cloud feedbacks and their coherence with temperature change may 


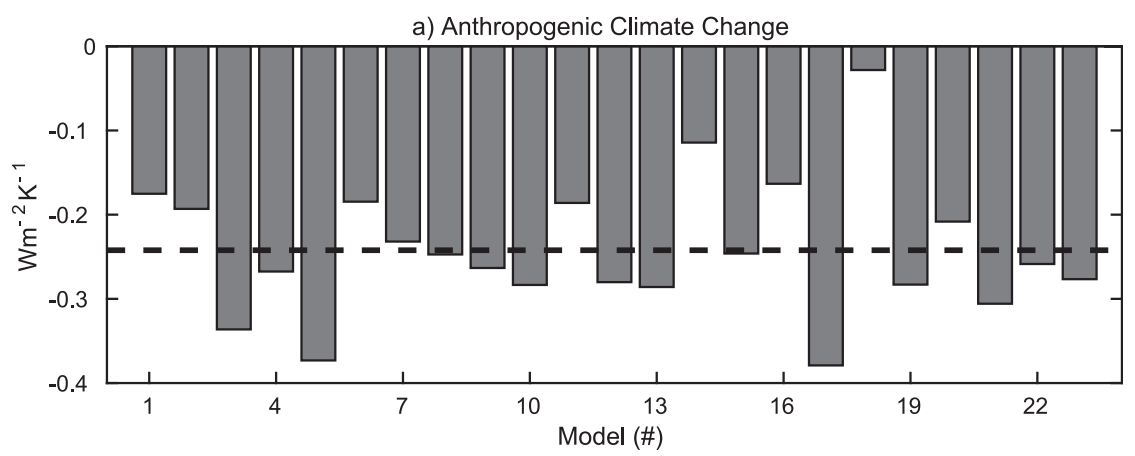

b) Internal Climate Variability

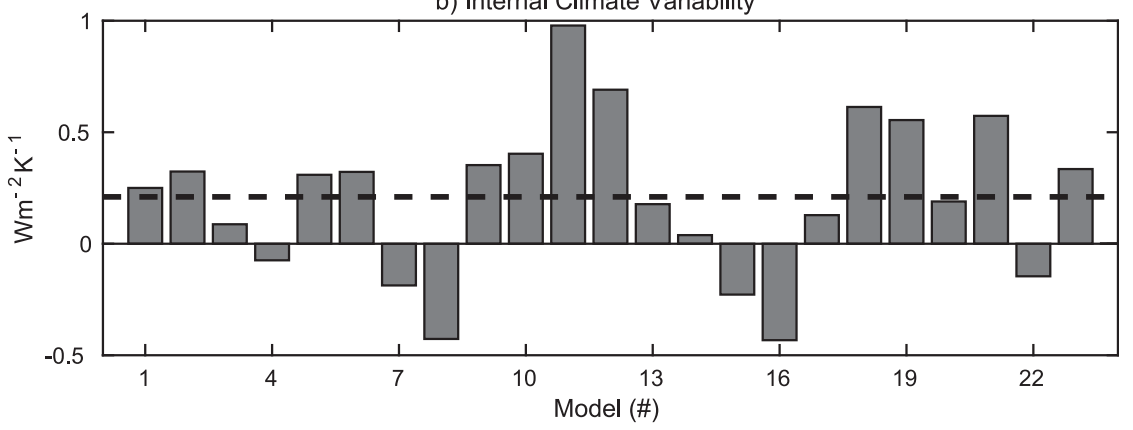

FIG. 7. As in Fig. 4, but for abrupt4xCO2 simulations.

differ between time scales, which warrants further investigation.

It is important to note that our methodology is not identical to that of Previdi (2010) and O'Gorman et al. (2012), since those studies made additional adjustments to cloud radiative forcing calculations that account for cloud masking effects (Soden et al. 2004; Soden et al 2008). Accounting for cloud masking in our work would increase the magnitude of $d R_{\mathrm{cld}} d d T_{s}$ for each model, but since the bias is systematic across models (Soden et al. 2004), it would not change the conclusion that the spread in $d R / d T_{s}$ is heavily influenced by the spread in $d R_{\mathrm{clr}} / d T_{s}$, especially for ACC.

Additionally, calculations by Previdi (2010) and O'Gorman et al. (2012) are produced from a single radiative transfer scheme, through the radiative kernel technique (Soden et al. 2008), while we use radiative fluxes produced from the unique radiative transfer scheme of each model. It has been shown that differences in model radiative parameterization contribute to intermodel spread in the SW component of $d R_{\mathrm{clr}} / d T_{s}$ (Collins et al. 2006; Pendergrass and Hartmann 2014; DeAngelis et al. 2015; Fildier and Collins 2015). Based on the methodology, our results may include this contribution to intermodel spread, while the findings by Previdi (2010) and O'Gorman et al. (2012) do not.

We further investigate $d R / d T_{s}$ spread by separating $d R_{\text {clr }} / d T_{s}$ and $d R_{\text {cld }} d d T_{s}$ into SW-only and LW-only components, indicated in the variable name with a corresponding subscript (i.e., $d R_{\text {cld,LW }} / d T_{s}$ for cloudy-sky, LW radiative cooling sensitivity). In Fig. $10, d R_{\mathrm{clr}, \mathrm{LW}} / d T_{s}$ and $d R_{\mathrm{clr}, \mathrm{sw}} / d T_{s}$ for each model are plotted against $d R_{\mathrm{clr}} / d T_{s}$ for ACC (Fig. 10a) and ICV (Fig. 10b). The same comparisons are made for the cloudy-sky components (Figs. 10c,d). As is evident from the linear regression slopes displayed in Fig. 10, the spread in the LW component accounts for the majority of the intermodel spread in $d R_{\mathrm{clr}} / d T_{s}$, with some contribution from spread in the SW component. DeAngelis et al. (2015), studying the radiative response to surface warming in isolation, found a more equal intermodel spread contribution from $d R_{\mathrm{clr}, \mathrm{LW}} / d T_{s}$ and $d R_{\mathrm{clr}, \mathrm{SW}} / d T_{s}$, but in agreement with our study, the former dominated. We find that the intermodel spread in $d R_{\mathrm{cld}} / d T_{s}$ is accounted for almost entirely by the spread in the LW component, which is greater for ICV $\left(\sim 2.2 \mathrm{~W} \mathrm{~m}^{-2}\right)$ compared to ACC $\left(\sim 1.2 \mathrm{~W} \mathrm{~m}^{-2}\right)$. The influence of clouds on SW absorption is small, explaining the lack of contribution from the SW component to the spread in $d R_{\text {cld }} / d T_{s}$ (Lambert and Webb 2008). The linear regression slope for each SW component is negative, or smaller than the uncertainty in the clear-sky ACC case, suggesting that $d W / d T_{s}$ is a dominant source of intermodel spread in the SW component of $d R / d T_{s}$. Water vapor enhances radiative cooling in total and in the LW, but also acts to increase SW absorption. 

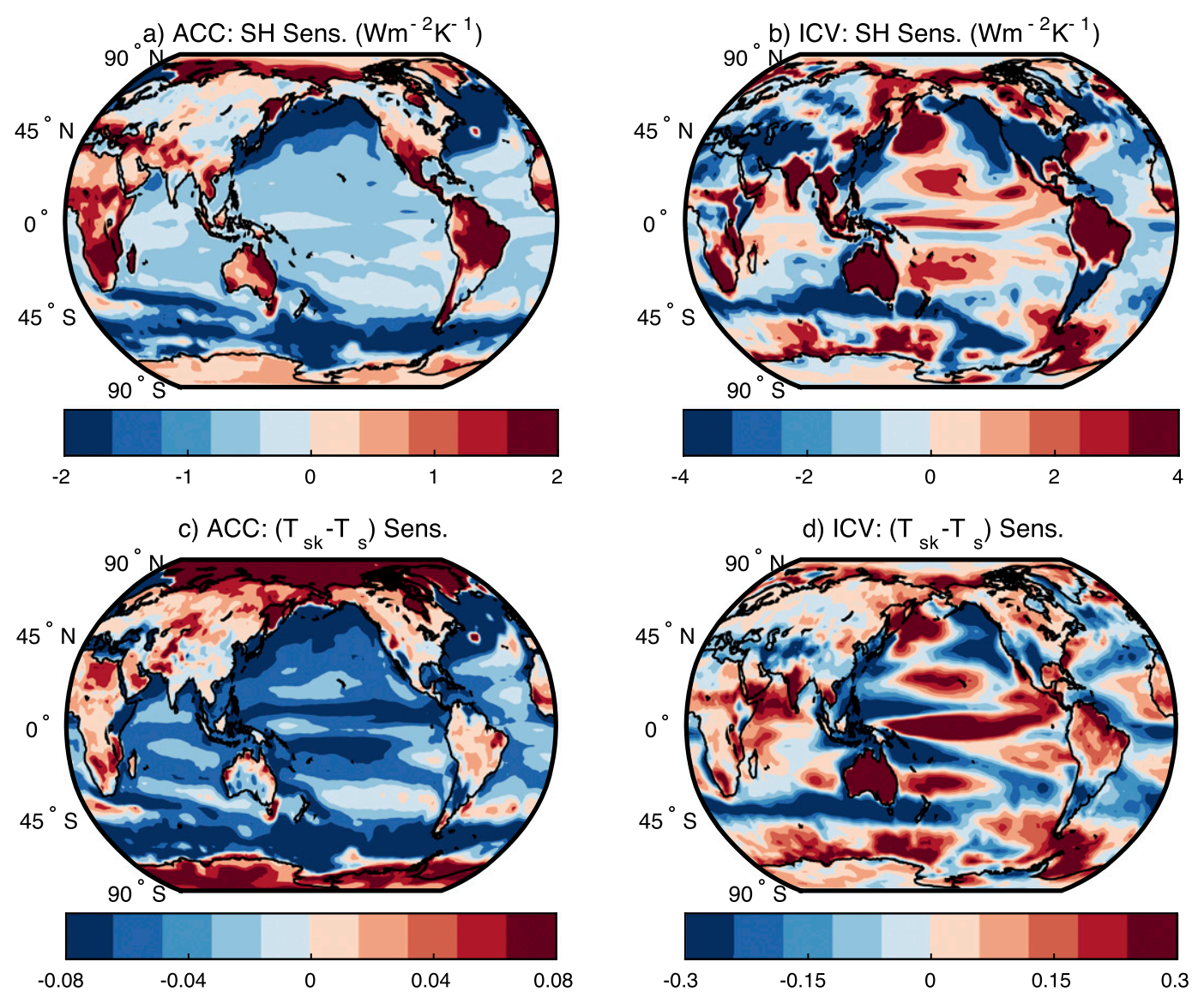

FIG. 8. Ensemble-mean linear regression of local $\Delta \mathrm{SH}$ to global-mean $\Delta T_{s}$ (local SH sensitivity) for $1 \mathrm{pctCO} 2$ simulations for (a) ACC and (b) ICV. Ensemble-mean linear regression of local changes in surface-air temperature difference $\left[\Delta\left(T_{\mathrm{sk}}-T_{s}\right)\right]$ to global-mean $\Delta T_{s}$ [local $\left(T_{\mathrm{sk}}-T_{s}\right)$ sensitivity] for (c) ACC and (d) ICV. All models are interpolated onto a standard $2^{\circ} \times 2^{\circ}$ grid. Note that the color bars differ for each panel and are saturated at the minimum and maximum color bar values.

The magnitude of spread in $d R_{\mathrm{clr}} / d T_{s}$, and dependency on LW versus SW components, is similar between ACC and ICV, and for both the 1 pctCO2 and abrupt4xCO2 simulations (not shown), indicating that climate feedbacks

a) Anthropogenic Climate Change

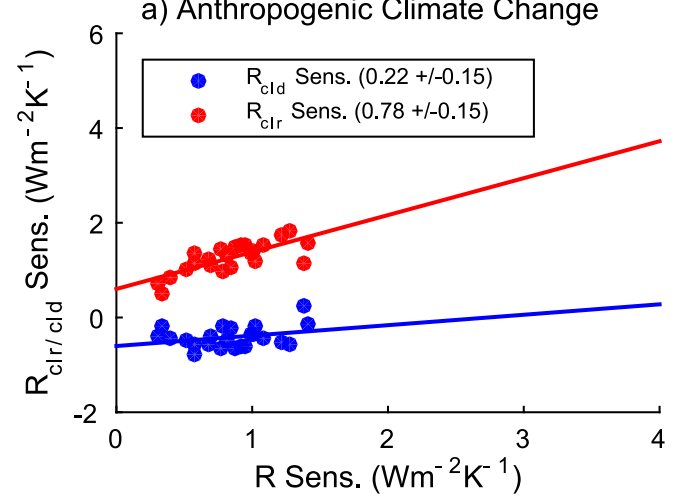

and not external forcing are mainly responsible for the intermodel spread in $d R / d T_{s}$. Past studies have demonstrated that $d R_{\mathrm{clr}} / d T_{s}$ is heavily dependent on water vapor (Stephens et al. 1994; Allan 2006; Stephens and Ellis

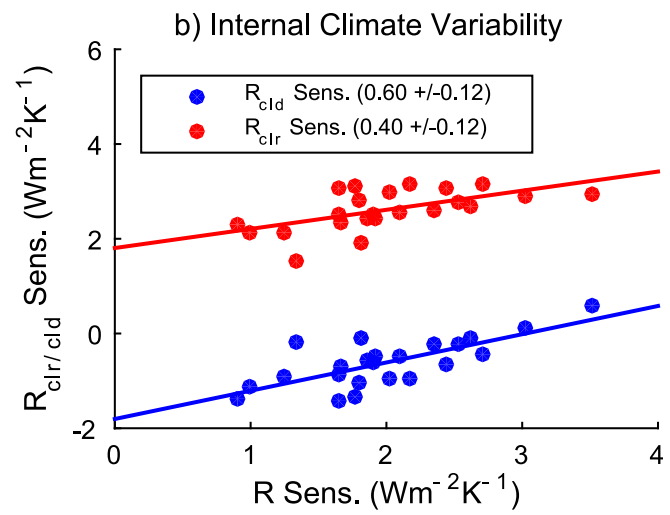

FIG. 9. Model comparison of global-mean $R_{\text {cld }}$ sensitivity vs $R$ sensitivity (blue) and global-mean $R_{\text {clr }}$ sensitivity vs $R$ sensitivity (red) for 1pctCO2 simulations for (a) ACC and (b) ICV. Linear least squares regression lines are shown, along with corresponding slopes and plus or minus one standard error. Each point represents a single model. 

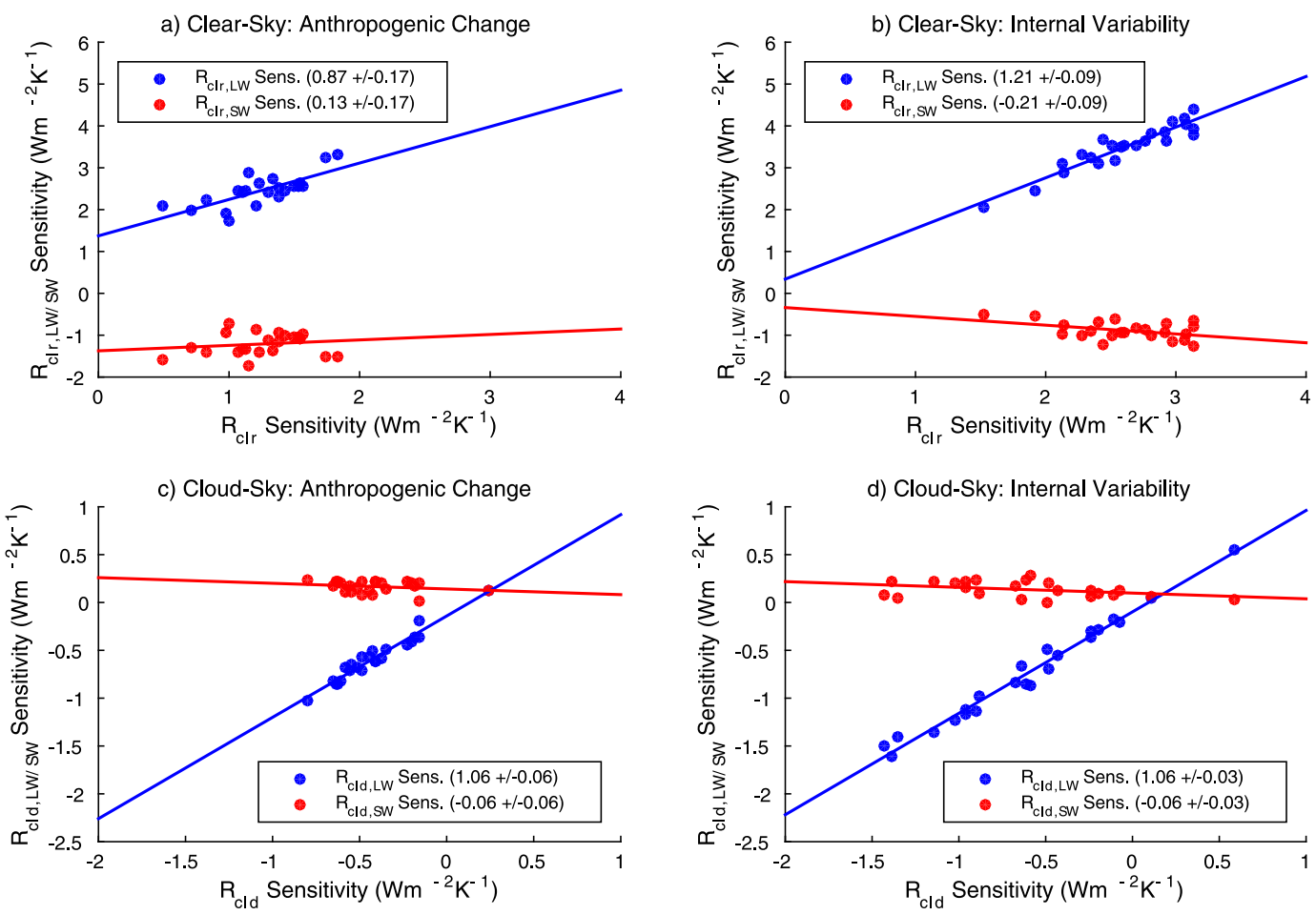

FIG. 10. Model comparison of global-mean $R_{\mathrm{clr}}$ sensitivity vs $R_{\mathrm{clr}, \mathrm{LW}}$ (blue) and $R_{\mathrm{clr}, \mathrm{SW}}$ (red) sensitivity for $1 \mathrm{pctCO} 2$ simulations for (a) ACC and (b) ICV. Model comparison of global-mean $R_{\text {cld }}$ sensitivity vs $R_{\text {cld,Lw }}$ (blue) and $R_{\text {cld,Sw }}$ (red) sensitivity for (c) ACC and (d) ICV. Linear least squares regression lines are shown along with corresponding slopes and plus or minus one standard error. Each point represents a single model.

2008). The presence of water vapor increases LW emission to the surface, which is only partially compensated for by increased SW absorption (Mitchell et al. 1987; Allan 2006). With respect to intermodel spread, however, the relationships of $d W / d T_{s}$ to spread in $d R_{\mathrm{clr}, \mathrm{LW}} / d T_{s}$ and $d R_{\mathrm{clr}, \mathrm{SW}} / d T_{s}$ offset each other, limiting the dependency of $d R_{\mathrm{clr}} / d T_{s}$ spread on $d W / d T_{s}$ spread for ICV, and almost eliminating the dependency entirely for ACC (not shown). Further investigation of the radiative cooling response to climate feedbacks, over both ACC and ICV time scales, using a technique like radiative kernels (Soden et al. 2008), is the next logical step toward defining the root causes of $d R / d T_{s}$ intermodel spread.

\section{Summary and discussion}

Using simulations from 23 CMIP5 models where $\mathrm{CO}_{2}$ is increased $1 \% \mathrm{yr}^{-1}$, and simulations where $\mathrm{CO}_{2}$ concentration is instantaneously quadrupled from preindustrial values and then held fixed, we have analyzed the physical constraints on the global hydrological cycle and the response of $P$ to anthropogenic climate change (ACC) versus internal climate variability (ICV). We have done so by comparing $d W / d T_{s} d P / d T_{s}, d R / d T_{s} d \mathrm{SH} / d T_{s}$, and the ratio of $L \Delta P$ to $\Delta R$ at annual-to-decadal versus multidecadal time scales. We show that the ensemble-mean $d W / d T_{s}$ is close to values predicted by the Clausius-Clapeyron equation, that the results are similar between ACC $\left(7.4 \% \mathrm{~K}^{-1}\right)$ and ICV $\left(7.6 \% \mathrm{~K}^{-1}\right)$, and that $d P / d T_{s}$ is similar in magnitude to $d R / d T_{s}$, supporting the argument outlined in previous studies that $\Delta P$ is constrained by the atmospheric energy budget.

More importantly, in the simulations with exponentially increasing $\mathrm{CO}_{2}, d R / d T_{s}$ and subsequently $d P / d T_{s}$ are smaller for ACC compared to ICV due directly to the effects of the increasing $\mathrm{CO}_{2}$ concentrations. In addition, $\Delta \mathrm{SH}$ contributes to the atmospheric energy balance and $d \mathrm{SH} / d T_{s}$ also differs between time scales, but because of the temperature dependency alone and not the $\mathrm{CO}_{2}$ forcing. Differences in intermodel spread between time scales are addressed, with clouds shown to be responsible for increased spread in $d P / d T_{s}$ at ICV compared to ACC time scales.

The constraints of $\Delta P$ in a warming climate include two distinct components: a "slow" direct response of $P$ to $\Delta T_{s}$ on time scales of years and a "fast" response of $P$ directly to external forcing, such as $\mathrm{CO}_{2}$, on time scales of weeks to months (Andrews et al. 2009; Bala et al. 2010; Frieler et al. 2011; Allan et al. 2014). Our finding that the largest $\mathrm{CO}_{2}$ effect on $P$ occurs on multidecadal 
time scales is not at odds with this concept. Rather, it shows that in a transient climate, the response of $P$ depends on the magnitude of the $\mathrm{CO}_{2}$ concentration change, and not just on the presence of $\mathrm{CO}_{2}$ forcing. Larger $\mathrm{CO}_{2}$ increases occur with ACC, leading to a reduction in $d P / d T_{s}$ compared to ICV. While separating the temperature and external forcing components as previous studies have done offers valuable insights into the constraints on $\Delta P$, understanding how the two components evolve together is of equal importance in a climate where $P$ continuously responds to both internal climate variability and externally forced change.

Our results ultimately highlight that the role of $\mathrm{CO}_{2}$ on limiting $\Delta R$ is minimal at subdecadal time scales; therefore, short-term trends in $\Delta P$ with warming are a poor indicator of long-term change. This underlines the importance of developing an observing system capable of detecting low-frequency climate variability. It is possible that other climate processes constrained by atmospheric radiative cooling changes include a response to $\mathrm{CO}_{2}$ that is unobservable in the short term. We have identified important distinctions between ACC and ICV, and related responses of $P$, that have implications for how we interpret both model results and our relatively limited record of global precipitation observations.

Acknowledgments. We thank three anonymous reviewers for their thorough comments and helpful suggestions. This research was supported by grants from the NASA Research Opportunities in Space and Earth Sciences (ROSES) program. The CMIP5 simulations were obtained from the Program for Climate Model Diagnosis and Intercomparison (PCMDI). We appreciate the work of this program to archive the data and thank each modeling group for providing the model output for the archive.

\section{REFERENCES}

Allan, R. P., 2006: Variability in clear-sky longwave radiative cooling of the atmosphere. J. Geophys. Res., 111, D22105, doi:10.1029/2006JD007304.

, C. Liu, M. Zahn, D. A. Lavers, E. Koukouvagias, and A. Bodas-Salcedo, 2014: Physically consistent responses of the global atmospheric hydrological cycle in models and observations. Surv. Geophys., 35, 533-552, doi:10.1007/ s10712-012-9213-z.

Allen, M. R., and W. J. Ingram, 2002: Constraints on future climate changes in climate and the hydrologic cycle. Nature, 419, 224-232, doi:10.1038/nature01092.

Andrews, T., P. M. Forster, and J. M. Gregory, 2009: A surface energy perspective on climate change. J. Climate, 22, 2557-2570, doi:10.1175/2008JCLI2759.1.

Arkin, P. A., T. M. Smith, M. R. P. Sapiano, and J. Janowiak, 2010: The observed sensitivity of the global hydrological cycle to changes in surface temperature. Environ. Res. Lett., 5, 035201, doi:10.1088/1748-9326/5/3/035201.

Bala, G., K. Caldeira, and R. Nemani, 2010: Fast versus slow response in climate change: Implications for the global hydrological cycle. Climate Dyn., 35, 423-434, doi:10.1007/ s00382-009-0583-y.

Bony, S., G. Bellon, D. Klocke, S. Sherwood, S. Fermepin, and S. Devil, 2013: Robust direct effect of carbon dioxide on tropical circulation and regional precipitation. Nat. Geosci., 6, 447-451, doi:10.1038/ngeo1799.

Collins, W. D., and Coauthors, 2006: Radiative forcing by wellmixed greenhouse gases: Estimates from climate models in the Intergovernmental Panel on Climate Change (IPCC) Fourth Assessment Report (AR4). J. Geophys. Res., 111, D14317, doi:10.1029/2005JD006713.

DeAngelis, A. M., X. Qu, M. D. Zelinka, and A. Hall, 2015: An observational radiative constraint on hydrologic cycle intensification. Nature, 528, 249-253, doi:10.1038/nature15770.

Donohoe, A., and D. S. Battisti, 2013: The seasonal cycle of atmospheric heating and temperature. J. Climate, 26, 4962-4980, doi:10.1175/JCLI-D-12-00713.1.

Fasullo, J. T., and K. E. Trenberth, 2008: The annual cycle of the energy budget. Part I: Global mean and land-ocean exchanges. J. Climate, 21, 2297-2312, doi:10.1175/ 2007JCLI1935.1.

Fildier, B., and W. D. Collins, 2015: Origins of climate model discrepancies in atmospheric shortwave absorption and global precipitation changes. Geophys. Res. Lett., 42, 8749-8757, doi:10.1002/2015GL065931.

Frieler, K., M. Meinshausen, T. Schneider von Deimling, T. Andrews, and P. Forster, 2011: Changes in global-mean precipitation in response to warming, greenhouse gas forcing and black carbon. Geophys. Res. Lett., 38, L04702, doi:10.1029/ 2010 GL045953.

Held, I. M., and B. J. Soden, 2006: Robust responses of the hydrological cycle to global warming. J. Climate, 19, 5686-5699, doi:10.1175/JCLI3990.1.

Huffman, G. J., R. F. Adler, D. T. Bolvin, and G. Gu, 2009: Improving the global precipitation record: GPCP version 2.1 . Geophys. Res. Lett., 36, L17808, doi:10.1029/2009GL040000.

John, V. O., R. P. Allan, and B. J. Soden, 2009: How robust are observed and simulated precipitation responses to tropical ocean warming? Geophys. Res. Lett., 36, L14702, doi:10.1029/ 2009GL038276.

Lambert, F. H., and M. J. Webb, 2008: Dependency of global mean precipitation on surface temperature. Geophys. Res. Lett., 35, L16706, doi:10.1029/2008GL034838.

,,-- M. Yoshimori, and T. Yokohata, 2015: The cloud radiative effect on the atmospheric energy budget and global mean precipitation. Climate Dyn., 44, 2301-2325, doi:10.1007/ s00382-014-2174-9.

Mitchell, J. F. B., C. A. Wilson, and W. M. Cunnington, 1987: On $\mathrm{CO}_{2}$ climate sensitivity and model dependence of results. Quart. J. Roy. Meteor. Soc., 113, 293-322, doi:10.1256/ smsqj. 47516.

Morice, C. P., J. J. Kennedy, N. A. Rayner, and P. D. Jones, 2012: Quantifying uncertainties in global and regional temperature change using an ensemble of observational estimates: The HadCRUT4 data set. J. Geophys. Res., 117, D08101, doi:10.1029/2011JD017187.

O'Gorman, P. A., R. P. Allan, M. P. Byrne, and M. Previdi, 2012: Energetic constraints on precipitation under climate change. Surv. Geophys., 33, 585-608, doi:10.1007/s10712-011-9159-6. 
Pendergrass, A. G., and D. L. Hartmann, 2014: The atmospheric energy constraint on global-mean precipitation change. J. Climate, 27, 757-768, doi:10.1175/JCLI-D-13-00163.1.

Previdi, M., 2010: Radiative feedbacks on global precipitation. Environ. Res. Lett., 5, 025211, doi:10.1088/1748-9326/5/2/ 025211.

Sherwood, S., and Q. Fu, 2014: A drier future? Science, 343, 737-739, doi:10.1126/science.1247620.

Soden, B. J., A. J. Broccoli, and R. S. Hemler, 2004: On the use of cloud forcing to estimate cloud feedback. J. Climate, 17, 3661-3665, doi:10.1175/1520-0442(2004)017<3661 OTUOCF $>2.0 . \mathrm{CO} ; 2$

- I. M. Held, R. Colman, K. M. Shell, J. T. Kiehl, and C. A. Shields, 2008: Quantifying climate feedbacks using radiative kernels. J. Climate, 21, 3504-3520, doi:10.1175/ 2007JCLI2110.1.

Stephens, G. L., and T. D. Ellis, 2008: Controls of global-mean precipitation increases in global warming GCM experiments. J. Climate, 21, 6141-6155, doi:10.1175/2008JCLI2144.1.

, A. Slingo, M. J. Webb, P. J. Minnett, P. H. Daum, L. Kleinman, I. Wittmeyer, and D. A. Randall, 1994: Observations of the Earth's radiation budget in relation to atmospheric hydrology: 4. Atmospheric column radiative cooling over the world's oceans. J. Geophys. Res., 99, 18585-18604, doi:10.1029/ 94JD01151.

Taylor, K. E., R. J. Stouffer, and G. A. Meehl, 2012: An overview of CMIP5 and the experiment design. Bull. Amer. Meteor. Soc., 93, 485-498, doi:10.1175/BAMS-D-11-00094.1.

Trenberth, K. E., J. Fasullo, and L. Smith, 2005: Trends and variability in column-integrated atmospheric water vapor. Climate Dyn., 24, 741-758, doi:10.1007/s00382-005-0017-4.

Vecchi, G. A., and B. J. Soden, 2007: Global warming and the weakening of the tropical circulation. J. Climate, 20, 4316-4340, doi:10.1175/JCLI4258.1.

Wentz, F. J., and M. Schabel, 2000: Precise climate monitoring using complementary satellite data sets. Nature, 403, 414-416, doi: $10.1038 / 35000184$.

- L. Ricciardulli, K. Hilburn, and C. Mears, 2007: How much more rain will global warming bring? Science, 317, 233-235, doi:10.1126/science.1140746.

Yang, F., A. Kumar, M. E. Schlesinger, and W. Wang, 2003: Intensity of the hydrological cycles in warmer climates. J. Climate, 16, 2419-2423, doi:10.1175/2779.1. 